\title{
Preliminary Study on the Application of Concentrated Solar Power in Metallurgy of Titanium
}

\author{
Jaroslav Kováčik ${ }^{1, * \mathbb{0}}$, Natália Mináriková ${ }^{1}$, Tomáš Dvorák ${ }^{1}$, Jose Rodríguez ${ }^{2}$, \\ Inmaculada Cañadas ${ }^{2}$, Klaled Saleh Al-Athel ${ }^{3} \mathbb{D}$, Peter Šugár 4 (D), Jana Šugárová 4 \\ and Štefan Emmer 5 \\ 1 Institute of Materials \& Machine Mechanics, Slovak Academy of Sciences, Dúbravská cesta 9, 84513 \\ Bratislava, Slovakia; ummsnmin@savba.sk (N.M.); tomas.dvorak@savba.sk (T.D.) \\ 2 PSA-Plataforma Solar de Almería, CIEMAT, Apartado 22, Ctra de Senes Km 4, 04200 Tabernas, Spain; \\ jrodriguez@psa.es (J.R.); icanadas@psa.es (I.C.) \\ 3 Mechanical Engineering Department, King Fahd University of Petroleum \& Minerals, \\ Dhahran 31261, Saudi Arabia; kathel@kfupm.edu.sa \\ 4 Institute of Production Technologies, Faculty of Materials Science and Technology, Slovak University of \\ Technology, J. Bottu 25, 91724 Trnava, Slovakia; peter.sugar@stuba.sk (P.Š.); jana.sugarova@stuba.sk (J.Š.) \\ 5 IVMA STU, Pionierska 15, 83102 Bratislava, Slovakia; emmer.ivmastu@gmail.com \\ * Correspondence: ummsjk@savba.sk; Tel.: +421-907-185088
}

Received: 27 June 2019; Accepted: 4 October 2019; Published: 10 October 2019

check for updates

\begin{abstract}
The applicability of concentrated solar power for metallurgy of titanium is discussed based on preliminary experimental works performed at Plataforma Solar de Almeria Spain, using solar furnace SF40 under protective argon atmosphere. As a starting material, titanium powder was used. The possibility of melting titanium compacts on yttria stabilized zirconia mat was investigated, and the effect of density and size of different green compacts was studied. It was observed that the time to achieve melting point is very short when concentrated solar power is used. The obtained results are expected to be similar for titanium sponge from which titanium powder is processed. After optimization of processing parameters, this will probably lead to a significant decrease of carbon footprint in the titanium ingots and castings production.
\end{abstract}

Keywords: concentrated solar power; titanium; solar metallurgy

\section{Introduction}

Current production of titanium ingots is exclusively done by the Kroll process [1]. In this process, rutile (natural or synthetic) or titania slag is chlorinated to produce titanium tetrachloride ( $\mathrm{TiCl}_{4}$ ) which is then reduced by magnesium. The result of the process is the titanium sponge that is further vacuum arc melted to the titanium ingots of desired purity.

Another possibility is to use the Armstrong process [2,3]. This low temperature process enables powder production of a commercially pure titanium and Ti6Al4V alloy by the reduction of titanium tetrachloride by sodium. The process produces powder particles of the "coral-like" morphology. Powders can be milled, consolidated and compacted by traditional powder metallurgy techniques [3]. Sheets and near net shape products are usually produced in this way. Powder is also used for metal injection molding and additive manufacturing. Certain problems in the process of the pure Ti consolidation are due to the presence of sodium in the powder inner pores.

Norgate et al. [4] stated that the light metals such as titanium and aluminum had the greatest "cradle-to-gate" environmental impacts in terms of Global Warming Potential (GWP) and Gross Energy Requirements (GER). They assessed that for titanium production GWP is of $35.7 \mathrm{~kg} \mathrm{CO}_{2} \mathrm{e} / \mathrm{kg}$ and GER 
of $361 \mathrm{MJ} / \mathrm{kg}$. The world produced $170 \mathrm{kt}$ of titanium in 2016. The overall carbon dioxide footprint seems to be small, but expected increased titanium production, due to the powder metallurgical technologies [5-7], indicates that any approach to minimize the titanium GWP is very important.

Renewable solar energy is one of the possible ways to solve this problem. Recently, it was proved that concentrated solar energy can be successfully used in the solar powder metallurgy of titanium, porous titanium, titanium alloys and compounds and welding of $\mathrm{Ti}_{6} \mathrm{Al}_{4} \mathrm{~V}$ [8-11]. García et al. [10] successfully sintered porous titanium foams in argon atmosphere using $\mathrm{NaCl}$ as soluble spacer. Titanium foams were fully sintered at lower temperature and shorter time than in conventional furnace sintering (porosity achieved ranges between $58 \%$ and $77 \%$ ). Kováčik et al. [9] prepared $\mathrm{TiC}-\mathrm{TiB}_{2}$ ceramic foams from the mixture of $\mathrm{Ti}+15 \mathrm{vol} . \% \mathrm{~B}_{4} \mathrm{C}$ powders via solar powder metallurgy. Porosity of the prepared ceramic foams was around $45 \%$, and ignition temperature of the self-propagating high temperature synthesis was found to be around $1380{ }^{\circ} \mathrm{C}$ for the solar powder metallurgy. Romero et al. [11] successfully welded sheets of $\mathrm{Ti}_{6} \mathrm{Al}_{4} \mathrm{~V}$ titanium alloy in the flush corner joint configuration in a controlled inert argon atmosphere.

Kováčik et al. [8] showed that it is possible to use concentrated solar energy for sintering of titanium powder in argon atmosphere without applying the pressure. Final porosity below $5 \%$ was achieved by varying the sintering temperature and time. Solar sintering gives shorter time in comparison with the common vacuum furnace. Furthermore, during calibration experiments, it was observed that titanium powder can be easily melted (Figure 1). The experiments were performed on a molybdenum plate which led to the spill of molten titanium owing to diffusion and formation of ( $\alpha \mathrm{Ti}$, Mo) solid solution above the transformation temperature of pure $\mathrm{Ti}-882^{\circ} \mathrm{C}$ [12].

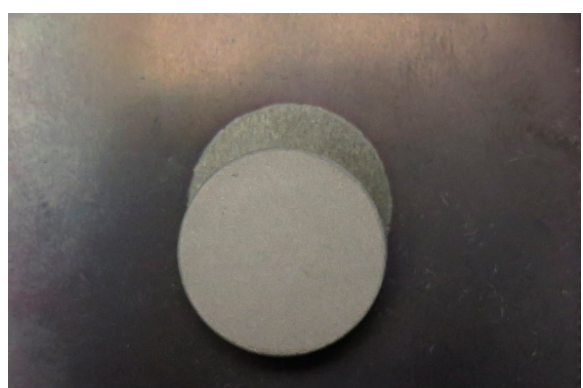

(a)

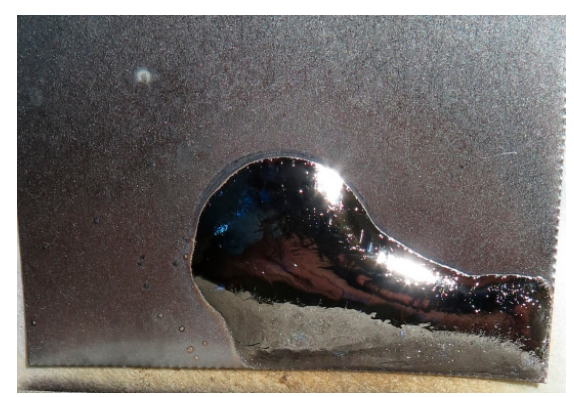

(b)

Figure 1. Titanium sample on molybdenum plate: (a) Small green compact prior to solar melting; (b) after solar melting during calibration tests.

It implies that it is necessary to check the possibility of melting the titanium powder green compacts in a solar furnace using a supporting material which reacts less with molten titanium. Refractory materials are more or less reacting with molten titanium, titanium alloys such as $\mathrm{Ti}_{6} \mathrm{Al}_{4} \mathrm{~V}$ or TiAl [13-16]. Yttria and zirconia are mostly used, but both still react with titanium and titanium alloy melts. Yttria is inert, but very expensive. On the basis of previous studies [13,14], it was proposed to use the porous yttria-stabilized zirconia mat for preliminary experiments to diminish the reaction as much as possible. Then, the working hypothesis was as follows: If these experiments are successful, it could be the first proof of the fact that the titanium sponge might be melted using solar metallurgy instead of the vacuum arc melting processes in order to produce titanium ingots. This would probably also lead to the decrease of titanium carbon footprint since the renewable solar energy will be used in the titanium metallurgy. Therefore, the aim of the research described in this paper was to investigate the possibility of solar melting of the Ti powder green compacts on an yttria-stabilized zirconia mat.

\section{Materials and Methods}

HDH (hydrogenated—dehydrogenated)Ti powder (purity 99.4\%, Kimet Special Metal Precision Casting Co., Ltd., Hengshui, China) was used for the investigations: Powder was of angular shape 
and the powder size distribution was determined using Fritch Analysette 22 laboratory equipment with $\mathrm{d}_{50}=25 \mu \mathrm{m}$ and $\mathrm{d}_{90}=46 \mu \mathrm{m}$. The powder was compacted by uniaxial pressing at $278 \mathrm{MPa}$ (small sample) and $120 \mathrm{MPa}$ (large sample). The typical geometry of green compacts before melting was as follows: diameter of 15.1/29.2 $\mathrm{mm}$ and height of 3.0/5.2 $\mathrm{mm}$ for the small and large samples, respectively. The compacts were weighted and finally the porosity was calculated using the known geometry. The calculated porosities were 35 and $41 \%$ respectively for the small and large samples.

Sintering experiments were performed in the SF40 horizontal axis solar furnace [17] in PSA under protective argon atmosphere, Almeria, Spain (Figure 2). SF40 is able to deliver up to $40 \mathrm{~kW}$ power at the peak concentration ratios exceeding $7000 \mathrm{~kW} / \mathrm{m}^{2}$ in the middle of the concentrated solar spot.

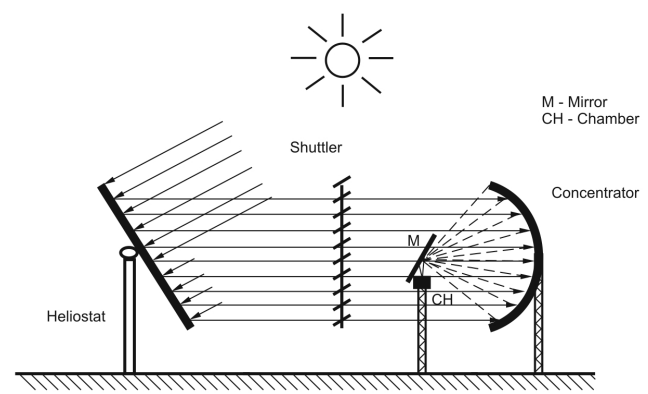

(a)

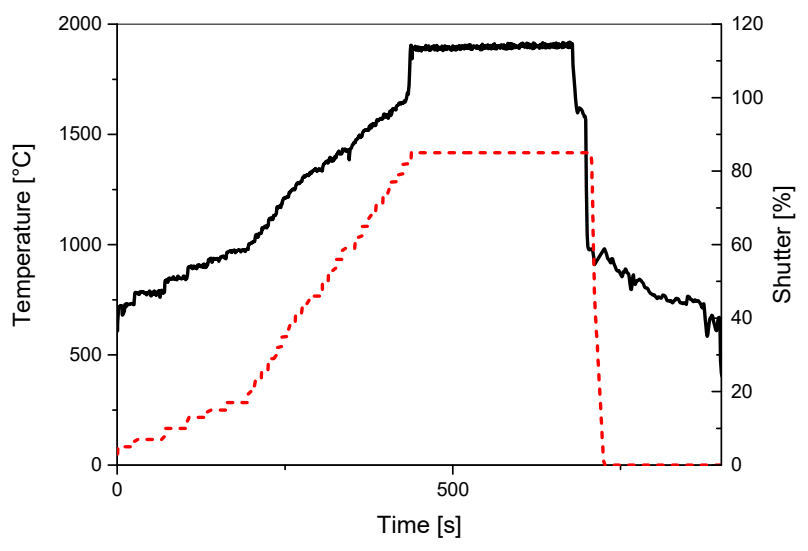

(b)

Figure 2. (a) Schematic picture of the solar experiment. (b) Heating/cooling curve of the solar melting of large titanium sample with 4 min dwell; the shutter opening (dash curve) is plotted on the secondary y axis. Heating rate $150 \mathrm{~K} / \mathrm{min}$; solar direct radiation $675 \pm 20 \mathrm{~W} / \mathrm{m}^{2}$.

The prepared samples were placed on the yttria-stabilized zirconia mat $(400 \times 400 \times 3 \mathrm{~mm})$ inside yttria-stabilized zirconia mat envelope with a $22 / 35 \mathrm{~mm}$ hole with regard to the sample size. The envelope was used to prevent possible leakage of molten titanium. The samples were positioned into a vacuum/gas chamber. The samples were placed at the optimal focusing distance with regard to the solar spot. The size of solar spot was approximately $120 \mathrm{~mm}$. At first, the chamber was evacuated using a rotary pump (down to $8 \times 10^{-1} \mathrm{~Pa}$ ), and subsequently the argon gas flow (150 L/hour under the pressure of $300 \mathrm{kPa}$, technical purity argon $99.998 \%$ with maximal impurities of $\mathrm{H}_{2} \mathrm{O} 5 \mathrm{ppm} \mathrm{mol} / \mathrm{mol}$ and of $\mathrm{O}_{2} 5 \mathrm{ppm} \mathrm{mol} / \mathrm{mol}$ ) was used during the tests. The protective argon atmosphere was also used for cooling the glass top of the chamber.

Constant heating rate of $150 \mathrm{~K} / \mathrm{min}$ was used during the experiments. After reaching the melting temperature of titanium $\left(1668{ }^{\circ} \mathrm{C}\right.$ [5]), the samples were held for 2 min (small) and 4 min (large sample) at a constant input power of solar flux. Finally, the samples were cooled down to the room 
temperature at a cooling rate of $100 \mathrm{~K} / \mathrm{min}$. The heating and cooling rates were manually controlled via shutter opening.

The sample temperature was measured using pyrometer (Infratherm IGA5-LO type, temperature range $400-2500^{\circ} \mathrm{C}$, spectral range $1.39 \mu \mathrm{m}$, aperture $\mathrm{D}=15 \mathrm{~mm}$, focusing distance $4500-7000 \mathrm{~mm}$ ) [18] using emissivity value of 0.95 [19]. After melting $\mathrm{Ti}$, the pyrometer readings did not give a precise temperature as emissivity is different for the molten Ti. However, it was still possible to keep constant temperature of the melt during the dwell time via pyrometer measurement. The molten state was also independently checked by non-calibrated IR camera (IRCAM EQUUS 327 SM PRO type) [18].

A typical heating/cooling curve of the solar melting of a large titanium sample with 4 min dwell at the heating rate of $150 \mathrm{~K} / \mathrm{min}$ is shown in Figure 2. Heating, dwell and cooling cycle took around $20 \mathrm{~min}$ for both experiments.

After the experiments, the Phoenix Nanotom X-ray micro tomography, USA, for nondestructive analysis of the internal structure of materials was used to evaluate the porosity value and to observe spatial porosity distribution in the solar melted samples.

LECO ONH836 analyzer was used to determine the concentration of the $\mathrm{O}, \mathrm{N}$ and $\mathrm{H}$ elements in the molted titanium samples. JEOL 7600F scanning electron microscope equipped with a Schottky thermal-emission cathode as well as the energy and wavelength spectrometers from Oxford Instruments was used for investigating the reaction of the molten titanium with yttria-stabilized zirconia mat.

\section{Results and Discussion}

The experiments proved that it is possible to completely melt the powder metallurgical compacts on the yttria-stabilized zirconia mat (Figure 3). The melting point was indicated by a sharp increase of the temperature measured by pyrometer at around $1670{ }^{\circ} \mathrm{C}$, as shown in Figure 2. It was also qualitatively confirmed by the infrared camera which enabled us to investigate qualitatively local differences in temperature distribution inside the sample, as indicated in Figure 4. The use of infrared camera enabled us to control the position of the middle of the solar spot with regard to the sample during experiments.

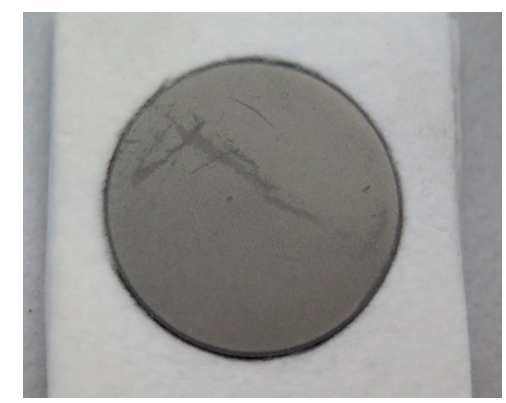

(a)

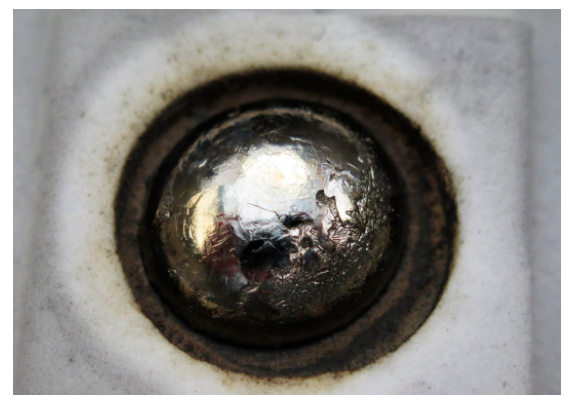

(b)

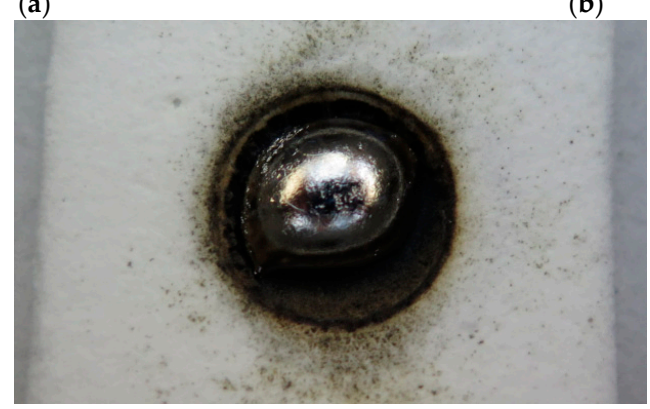

(c)

Figure 3. Titanium samples on/in yttria-stabilized zirconia mat: (a) Large green compact with diameter of $29.2 \mathrm{~mm}$ and height of $5.2 \mathrm{~mm}$ prior to solar melting; (b) large droplet after solar melting and (c) small droplet after solar melting. 


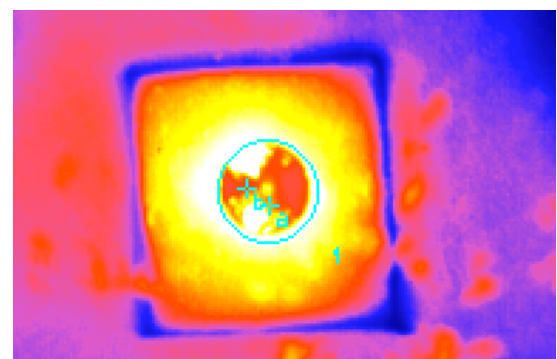

(a)

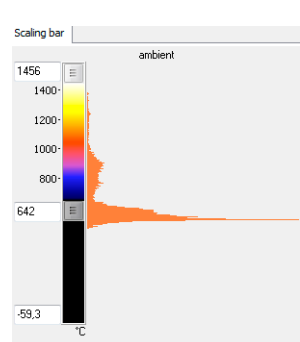

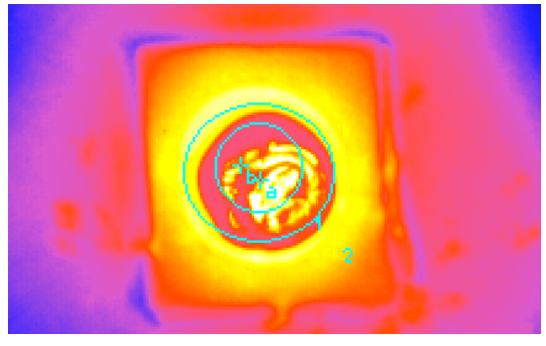

(b)

Figure 4. Typical distribution of temperature in molten titanium samples captured by IR camera during solar melting: (a) green diameter of $15.1 \mathrm{~mm}$ and height of $3.0 \mathrm{~mm}$; (b) green diameter of $29.2 \mathrm{~mm}$ and height of $5.2 \mathrm{~mm}$. The non-calibrated temperature scale is in the middle.

The experiments confirmed that, within $20 \mathrm{~min}$, it is possible to heat the green powder compact up to the melting temperature, hold the samples for 2 or 4 min according to the sample size, and cool them to the room temperature under protective argon atmosphere. The mass of the used samples was around $1.6 \mathrm{~g}$ for the small one, and $9.2 \mathrm{~g}$ for the large one. This implies that not only less energy but also a shorter time can be expected in the case of solar metallurgy of titanium in comparison with the vacuum arc melting technology after optimization of the technology for industrial scale.

Figure 3 indicates that after melting, the original disk shape of samples changes to the droplet shape. The droplet shape is the result of the minimizing the entropy via minimizing the surface to the volume ratio of the melt. This was also confirmed by X-ray tomography. As Figure 5 indicates, the small sample final shape is that of an irregular droplet. The wetting angle above $90^{\circ}$ was observed at the rough yttria-stabilized zirconia mat-argon-molten titanium triple point. This value indicates low wetting and relatively low interactions through the interface, and is consistent with the results observed by Zhu et al. [14] for porous and rough interfaces between the molten titanium and yttria-stabilized zirconia substrates at $1700{ }^{\circ} \mathrm{C}$.

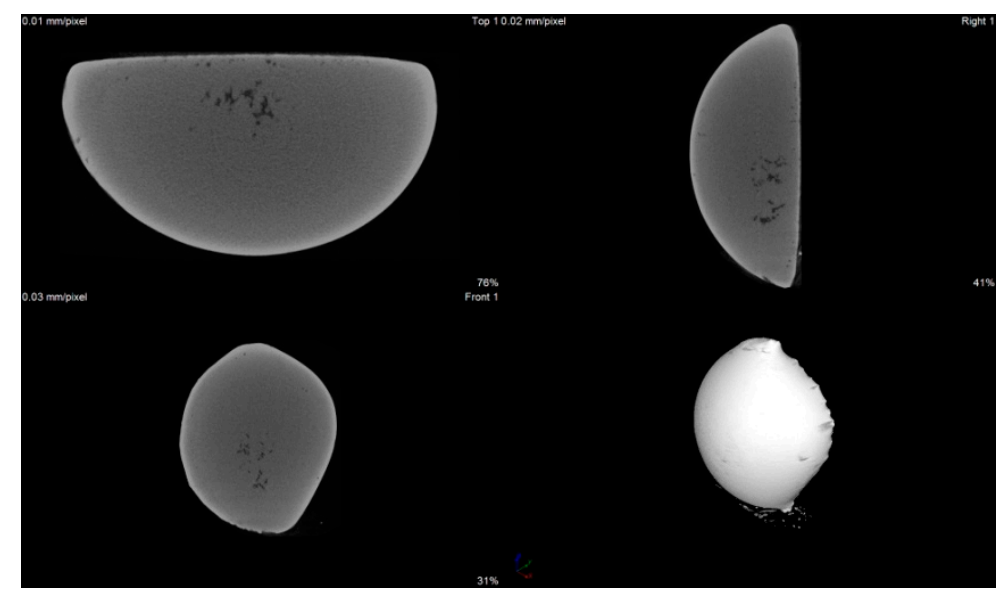

Figure 5. X-ray micro tomography of small droplet after solar melting: cuts in X, Y, Z planes and 3D picture of droplet. Final porosity $2.4 \%$.

Some local interaction probably took place owing to the impurities on the surface of the used yttria-stabilized zirconia mat (water and gas adhered to the surface/volume). This can explain the irregular final shape of the small sample.

From an industrial point of view, solid titanium needs to be fully dense. Since the technology is not optimized yet, it was necessary to determine porosity level of samples (Table 1). As the experiments were performed in argon atmosphere (possible gas entrapping inside the melt), it was also necessary to determine the precise information about spatial distribution of porosity and size of pores (Figure 5). X-ray tomography showed that some residual porosity is trapped inside the small sample (2.4\% final 
porosity). In that case, pores are small (of a micro meter size), and the gas is entrapped inside the sample. On the contrary, in case of a large sample (3.7\% final porosity), the largest porosity bubbles of a millimeter in size are in the vicinity of the upper surface of the droplet, as shown in Figure 6. If the sample is either held on the melting temperature for a longer time, or the temperature of the melt is increased, the gas bubbles will probably coalescence with the surrounding atmosphere and disappear. It can be concluded that, via the complex optimization of the dwell temperature of the melt and dwell time, porosity can be probably almost diminished.

Table 1. Geometry, porosity and final porosity of the investigated titanium samples.

\begin{tabular}{cccccc}
\hline Sample & Geometry (mm) & Weight $(\mathbf{g})$ & Porosity $(\%)$ & Final Porosity (\%) & Dwell Time (min) \\
\hline small & $\varphi 15.1 \times 3.0$ & 1.6 & 35 & 2.4 & 2 \\
large & $\varphi 29.2 \times 5.2$ & 9.2 & 41 & 3.7 & 4 \\
\hline
\end{tabular}

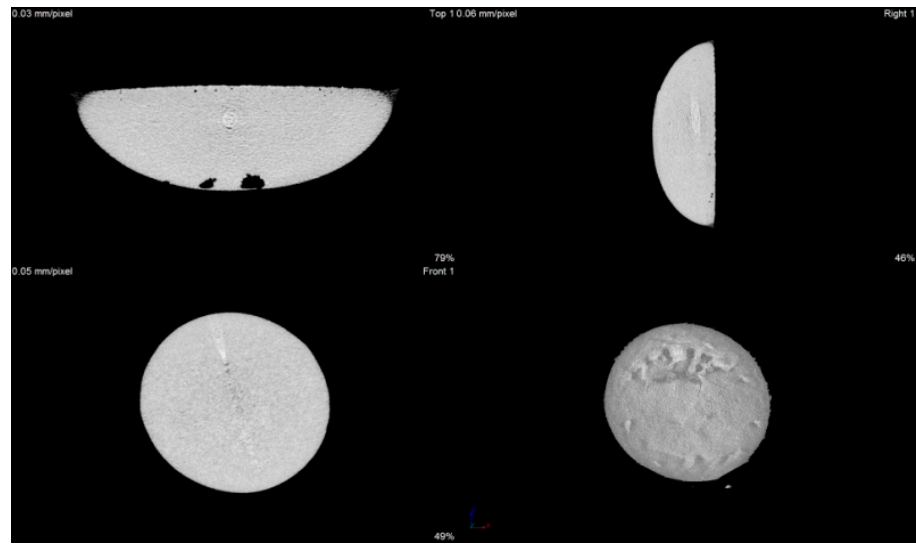

Figure 6. X-ray micro tomography of large droplet after solar melting: cuts in X, Y, Z planes and 3D picture of droplet. Final porosity 3.7\%.

LECO ONH836 analyzer was used to determine the concentration of the $\mathrm{O}, \mathrm{N}$ and $\mathrm{H}$ elements in the melted titanium samples. Analysis showed (Table 2) that the concentration of oxygen increased during solar melting owing to the reaction with the yttria-stabilized zirconia mat, even in comparison to the results observed during solar sintering of the same titanium powder type for $30 \mathrm{~min}$ at $1329^{\circ} \mathrm{C}$ [8]. As for the nitrogen and hydrogen concentrations, almost no significant changes were observed in comparison with solar sintering. It can be concluded that the final concentration of $\mathrm{O}, \mathrm{N}$ and $\mathrm{H}$ is ruled primarily by their concentration in the used HDH Ti powder and by interaction of molten titanium with the yttria-stabilized zirconia mat.

Table 2. ONH chemical analysis results for melted titanium samples in solar furnace.

\begin{tabular}{cccccc}
\hline Sample & O (wt.\%) & N (wt.\%) & H (wt.\%) & Final Porosity (\%) & Dwell Time (min) \\
\hline Powder & 0.54 & 0.026 & 0.036 & - & - \\
Small & 0.59 & 0.033 & 0.005 & 2.4 & 2 \\
Large & 0.64 & 0.035 & 0.004 & 3.7 & 4 \\
Small sintered [8] & 0.57 & 0.034 & 0.000 & 5 & $30\left(1329^{\circ} \mathrm{C}\right)$ \\
\hline
\end{tabular}

Scanning electron microscopy confirmed that the molten titanium surface in contact with the $y$ ttria-stabilized zirconia mat reacted with the mat elements, so that residual parts of mat were clearly visible on the samples surface after cleaning in ethanol (Figure 7). Larger sample size together with longer dwell time led to an increased reaction with the yttria-stabilized zirconia mat. Figure 8 indicates that, besides significant oxygen presence on the surface, localized zirconia fibers could also be observed on the sample surface. Increased concentration of oxygen was also clearly visible in the zirconia fibers. 
The area analyses were performed at three different locations, and the average concentration of the observed elements were determined (Table 3) for both samples on the upper surface, and also on the bottom reaction surface. The oxygen concentration (in wt.\%) raised almost twice on the reaction surface in comparison with the upper surface. On the reaction surface, zirconium and yttrium were also observed.

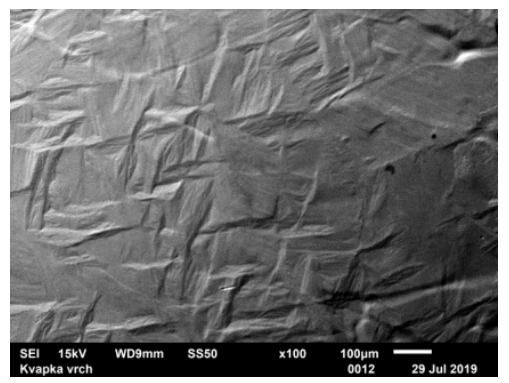

(a)

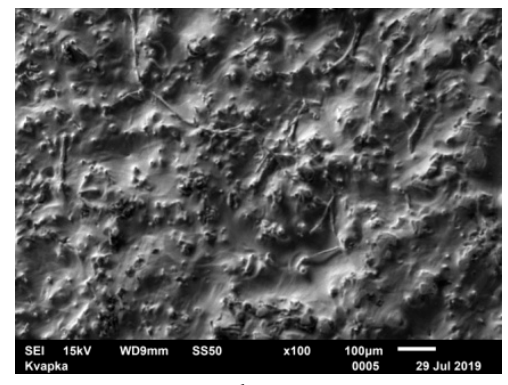

(b)

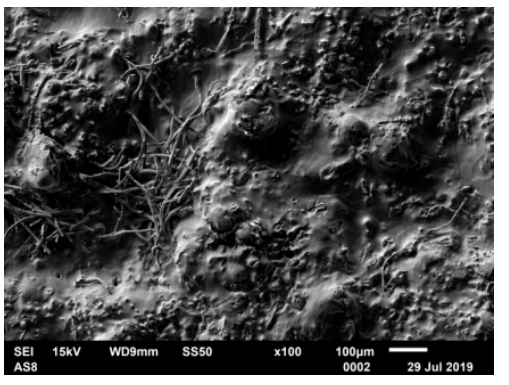

(c)

Figure 7. The surfaces of titanium samples after solar metallurgy (SEM): (a) small sample upper surface; (b) small sample reaction surface; (c) large sample reaction surface.

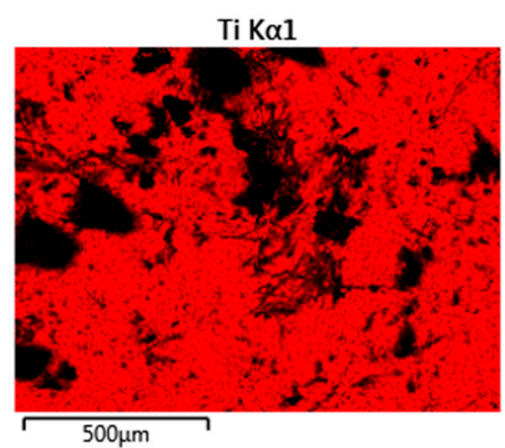

(a)

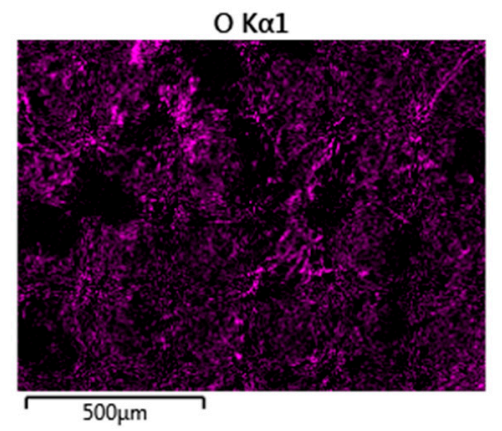

(b)

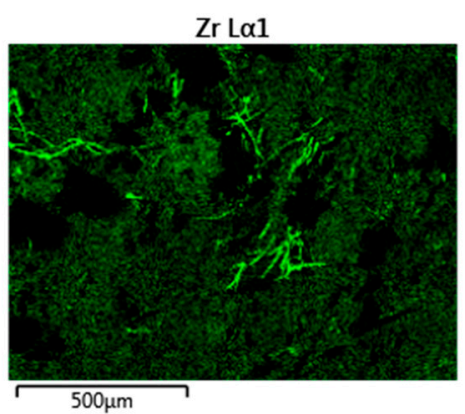

(c)

Figure 8. Element composition map of molted large Ti sample (SEM, EDS analysis) (a) titanium; (b) oxygen; (c) zirconium.

Table 3. EDS chemical area analysis results for melted titanium samples in solar furnace.

\begin{tabular}{ccccc}
\hline Sample & O (wt.\%) & Ti (wt.\%) & Zr (wt.\%) & Y (wt.\%) \\
\hline Small upper surface & $2.96 \pm 0.42$ & $97.04 \pm 0.42$ & - & - \\
Small reaction surface & $4.16 \pm 1.15$ & $90.11 \pm 1.83$ & $5.16 \pm 0.38$ & $0.57 \pm 0.32$ \\
Large upper surface & $6.09 \pm 0.69$ & $93.91 \pm 0.69$ & - & - \\
Large reaction surface & $11.10 \pm 0.39$ & $79.76 \pm 1.55$ & $8.21 \pm 1.40$ & $0.94 \pm 0.35$ \\
\hline
\end{tabular}

It can be concluded that the reaction of molten titanium with the yttria-stabilized zirconia mat significantly increases oxygen content on the reaction surface. On the contrary the observed volumetric increase was relatively small.

To summarize, it was confirmed that solar metallurgy of titanium is possible. Furthermore, it is necessary to determine the proper solar metallurgy parameters (heating rate, dwell temperature of the melt and dwell time) for required weight for titanium castings/ingots. It will be the subject of the next research together with the possibility to melt compressed titanium sponge using concentrated solar power. Only after these works are finished can it be precisely determined in what amount the carbon footprint of titanium production could be decreased by solar metallurgy. 


\section{Conclusions}

The titanium green compacts were successfully melted using SF40 solar furnace under protective argon atmosphere at PSA, Almeria, Spain. No flow of molten titanium was observed when the yttria-stabilized zirconia mat substrate was used. Two green compact disks of sizes of $\varnothing 15.1 \times 3.0 \mathrm{~mm}$ and $\varnothing 29.2 \times 5.2 \mathrm{~mm}$ were melted. The melting times were significantly short for both of them (around $20 \mathrm{~min}$ to melt $1.6 \mathrm{~g}$ and $9.2 \mathrm{~g}$ of titanium, respectively).

The final shape of the samples was changed owing to the minimizing of the surface to volume ratio. Small sample droplet was irregular. X-ray tomography enabled us to calculate final porosities, which were $2.4 \%$ for the small sample and $3.7 \%$ for the large one. In the small sample, the porosity is incorporated mostly within the sample volume. In the large sample, the porosity is localized in the vicinity of the upper surface of the droplet. It can be expected that optimization of the dwell temperature of the melt and the dwell time can significantly diminish the porosity.

Furthermore, reaction of the molten titanium with the yttria-stabilized zirconia mat was observed. This reaction significantly increased the oxygen content on the reaction surface. On the contrary, the observed volumetric increase was small in the case of the used short dwell times. Principally, there was no ceramic mold material completely resistant to reactions with molten titanium. Therefore, increased attention was also paid to non-oxide materials such as graphite, zirconate refractories and nitrides. Thanks to the composite coating method, the cost of the titanium casting can be reduced by controlling the interfacial reactions [16].

The presented results could be significant from the point of view of climatic changes. After optimization and proper application in the titanium production, utilization of renewable solar energy can decrease the carbon footprint of titanium ingot production. Of course, the technology can be used only in the titanium producing countries where solar energy can be effectively employed. In the case of bad weather, the process can be stopped, and then it can continue again in the case of good weather, most probably without a decrease in quality. It currently concerns China, Kazakhstan, India, USA, Australia and Saudi Arabia. Owing to shorter melting times, the results will lead to a significant decrease in titanium costs. The industrial exploitation and development of the solar metallurgy of titanium and titanium alloys will need more effort in the field of scientific and technological base research in the near future.

Author Contributions: Validation and formal analysis, J.Š.; sample preparation, N.M.; X-ray tomography T.D.; writing—original draft preparation, J.K.; writing—review and editing, P.Š.; solar melting, J.R. and I.C.; project administration, J.K.; funding acquisition, J.K., Š.E. and K.S.A.-A.

Funding: Financial support by the Access to Research Infrastructures activity in the 7th Framework Programme of the EU (SFERA Grant Agreement n. 228296) is gratefully acknowledged. Financial support of the SFERA II project-Transnational Access activities (EU 7th Framework Programme Grant Agreement $n^{\circ}$ 312643) is also gratefully acknowledged. Slovak Grant Agency VEGA grant 2/0044/17 financial support is gratefully acknowledged. This research is also funded by KSA Direct Funding Research Grant No. DF181016 of King Fahd University of Petroleum \& Minerals, Saudi Arabia.

Conflicts of Interest: The authors declare no conflicts of interest.

\section{References}

1. Kroll, W. Verformbare Legierungen des Titans. Z. Met. 1937, 29, 189-192.

2. Armstrong, D.R.; Borys, S.S.; Anderson, R.P. Method of Making Metals and Other Elements from the Halid Vapor of the Metal. U.S. Patent 5,958,106, 1999.

3. Araci, K.; Mangabhai, D.; Akhtar, K. Production of titanium by the Armstrong Process ${ }^{\circledR}$. Titan. Powder Metall. 2015, 149-162.

4. Norgate, T.; Jahanshahi, S.; Rankin, W. Assessing the environmental impact of metal production processes. J. Clean. Prod. 2007, 15, 838-848. [CrossRef]

5. Qian, M. (Ed.) Powder processing, Consolidation and Metallurgy of Titanium Ti (PM Titanium 2011). Key Eng. Mater. 2012, 520, 1-350. 
6. Balog, M.; Viskic, J.; Krizik, P.; Schauperl, Z.; Stanec, Z.; Snajdar, M.; Catic, A. CP Ti Fabricated by Low Temperature Extrusion of HDH Powder: Application in Dentistry. Key Eng. Mater. 2016, 704, 351-359. [CrossRef]

7. Šugár, P.; Kováčik, J.; Šugárová, J.; Ludrovcová, B. A Study of Laser Micromachining of PM Processed Ti Compact for Dental Implants Applications. Materials 2019, 12, 2246. [CrossRef] [PubMed]

8. Kováčik, J.; Emmer, Š.; Rodríguez, J.; Canadas, I. Sintering of HDH Ti powder in a solar furnace at Plataforma Solar de Almeria. J. Alloys Compd. 2017, 695, 52-59. [CrossRef]

9. Kováčik, J.; Dvorák, T.; Emmer, Š.; Rodríguez, J.; Canadas, I. Solar Powder Metallurgy: Preparation of TiC-TiB2 ceramic foam. In IOP Conference Series: Materials Science and Engineering; IOP Publishing: Bristol, UK, 2018; Volume 416, p. 012032.

10. García, I.; Gracia-Escosa, E.; Bayod, M.; Conde, A.; Arenas, M.; Damborenea, J.; Romero, A.; Rodríguez, G. Sustainable production of titanium foams for biomedical applications by Concentrated Solar Energy sintering. Mater. Lett. 2016, 185, 420-423. [CrossRef]

11. Romero, A.; García, I.; Arenas, M.A.; López, V.; Vázquez, A. Ti6Al4V titanium alloy welded using concentrated solar energy. J. Mater. Process. Technol. 2015, 223, 284-291. [CrossRef]

12. Murray, J.L. The Mo-Ti (Molybdenum-Titanium) system. Bull. Alloy Ph. Diagr. 1981, 2, 185-192. [CrossRef]

13. Frueh, C.; Poirier, D.R.; Maguire, M.C.; Harding, R.A. Attempts to develop a ceramic mould for titanium casting-A review. Int. J. Cast Met. Res. 1996, 9, 233-239. [CrossRef]

14. Zhu, J.; Kamiya, A.; Yamada, T.; Shi, W.; Naganuma, K.; Mukai, K. Surface tension, wettability and reactivity of molten titanium in Ti/yttria-stabilized zirconia system. Mater. Sci. Eng. A 2002, 327, 117-127. [CrossRef]

15. Jia, Q.; Cui, Y.Y.; Yang, R. A study of two refractories as mould materials for investment casting TiAl based alloys. J. Mater. Sci. 2006, 41, 3045-3049. [CrossRef]

16. Fan, J.; Liang, L.; Liu, Z.; Li, Y.; Li, Y.; Gao, H.; Wu, S.; Wang, Y.; Wang, X. Recent research and development of mould materials for casting TiAl alloys. Mater. Sci. Technol. 2019, 35, 891-899. [CrossRef]

17. Rodríguez, J.; Canadas, I.; Zarza, E. New PSA high concentration solar furnace SF40. In AIP Conference Proceedings; AIP Publishing: Melville, NY, USA, 2016; Volume 1734, p. 070028. [CrossRef]

18. Marzo, A.; Ballestrín, J.; Barbero, J.; Cañadas, I.; Rodriguez, J. Solar blind pyrometry not relying on atmospheric absorption bands. Sol. Energy 2014, 107, 415-422. [CrossRef]

19. Luo, S.; Yang, Y.; Schaffer, G.; Qian, M. Calibration of temperature measurement by infrared pyrometry in microwave heating of powder materials: An exothermic reaction based approach. J. Microw. Power Electromagn. Energy 2013, 47, 5-11. [CrossRef] [PubMed] 